\title{
Chapter 13 \\ Central Banking Practices in the Digital Era: Salient Challenges, Lessons, and Implications
}

\author{
Solikin M. Juhro
}

\begin{abstract}
The complexity and uncertainty of issues faced by central banks have and will continue to evolve in line with the advancement of digital technology. Navigating central banking practices in the digital era, therefore, is a very challenges task that requires the central bank's ability to create breakthroughs and orchestrate policy innovations. While the central bank policy mix is still a viable strategy, central banks are required to operate beyond conventional wisdom, with novel practices. Optimizing the benefits of technological advances and becoming a relevant regulator in the digital era must anchor the central bank's strategy in the future.
\end{abstract}

Keywords Central bank policy $\cdot$ Digital transformation $\cdot$ Central bank digital currency

\section{Introduction}

The two decades prior to the Global Financial Crisis (GFC) in 2008/09 witnessed a shift in the focus of central banks towards achieving and maintaining price stability. On one hand, the shift was in response to overcoming high inflation, while simultaneously providing greater central bank independence from the earlier period of government control. This was also consistent with emerging public perception concerning the importance of strong governance in terms of macroeconomic policy practices, including central bank policy. Academically, strengthening central bank policy governance was in line with rational expectations theory, policy consistency using a policy rule approach and the importance of transparency when forming expectations (Barro and Gordon 1983). This mindset encouraged central banks in many jurisdictions to apply monetary policy with price stability as the overriding objective, otherwise known as the Inflation Targeting Framework (ITF), encompassing standard and flexible ITF.

Notwithstanding, the Global Financial Crisis in 2008/09 (GFC) upended those central banking theories and practices. Not because ITF-based central bank policy

S. M. Juhro (凶)

Bank Indonesia, Jakarta, Indonesia 
had failed, in fact ITF had successfully brought inflation down to low levels, which, accompanied by low interest rates, stimulated solid economic growth and activity. The problem was that prolonged economic stability and boom periods contributed to rapid credit expansion and asset price bubbles affecting shares and housing, while accelerating leverage. Finance accelerated to the extent that the financial cycle amplified the economic cycle. Economic stability had created financial system instability, leading to the biggest crisis in 2008-2009 since the Great Depression of the 1930s. Evidently, price stability alone is insufficient to maintain macroeconomic stability if financial system stability has not been maintained; "there is no macrostability without financial stability." Financial frictions are inevitable due to information asymmetry, financial product innovation, price setting and valuation as well as risk-taking, leaving the financial system in a constant state of imbalance that accelerates the financial cycle and increases vulnerability to systemic risk (Warjiyo \& Juhro 2019; Juhro and Goeltom 2015).

Consequently, the GFC reminded central banks of their original mandate at inception, namely to achieve price (and exchange rate) stability and support financial system stability. Central bank credibility and the established ITF framework were a solid foundation upon which the dual mandate could be achieved. This was not sufficient, however. Macro-financial linkages demand a macroprudential policy response from the central bank to mitigate procyclicality between the financial sector and economic activity that leads to economic and financial crises, such as the GFC. Foreign exchange intervention policy and foreign capital flow management are also required to stabilise exchange rates under a flexible regime. Such developments encouraged many central banks to apply macroprudential policies and foreign capital flow management to strengthen monetary policy effectiveness. In short, a monetary and macroprudential policy mix, together with foreign capital flow management, represent a new paradigm for central banks after the GFC, including Bank Indonesia since 2010. Such innovation in terms of central bank policy practices demands the development of solid underlying theories and empirical studies (Warjiyo and Juhro 2019; Warjiyo 2021).

The fact that a crisis is an unprecedented event that potentially distorts economic welfare is shown by the emergence of the COVID-19 pandemic at the end of 2019. For the first time since the Great Depression of the 1930s, both developed and developing countries are facing the Covid-19 pandemic. The Covid-19 pandemic has caused enormous pressure on the economy both globally and nationally; reflected in world economic growth that is predicted to contract around 4\% in 2020. Extraordinary economic policies including the provision of very large economic stimulus by fiscal and monetary authorities have not been able to withstand the economic downturn of many countries.

Changes in the strategic environment do not stop there, however. The complexity and uncertainty of issues faced by central banks have and will continue to evolve in line with the advancement of digital technology. By its very nature, digital technology develops with rapidity, is transformative and influences various aspects of our lives. Ultimately, digital transformation is part of the digital technology development 
process, viewed as "the total and overall effect of digitalisation on the public". Digitisation has facilitated digitalisation, thus providing greater opportunity to transform and evolve existing business models, socio-economic structures, laws and policy measures, organisational patterns, cultural barriers and so on (Khan 2016; Collin et al. 2015). Digital transformation is fundamentally a phenomenon of disruption that is inextricably linked to the inevitable development and revolution of industrial technology. Klaus Schwab (2017) introduced the Industrial Revolution 4.0 concept that has fundamentally disrupted the lives and work of everyone. Three industrial revolutions have taken place before, but none boasted the scope and complexity of the Industrial Revolution 4.0. The advancement of new technology that integrates the physical, digital and biological worlds has impacted all scientific, economic, industrial and government disciplines. Several technology platforms across various fields have experienced rapid breakthroughs thanks to the advancement of technology during the Industrial Revolution 4.0, including the Internet of Things (IoT), big data analytics, artificial intelligence, blockchain technology and cybersecurity. ${ }^{1}$

The development of various technologies has changed public and corporate behaviour in terms of performing transactions and conducting economic activity. E-commerce activity is also playing a larger role in supporting the development of increasingly interconnected economic sectors. In this regard, banking activity and other financial services are expected to optimise the use of technology to meet the customers' needs and compete with the FinTech industry. This will ultimately influence the response, transmission mechanisms and effectiveness of central bank policy. Therefore, central banks must anticipate such developments, including the emergence of digital currency, either one issued by private sector (cryptocurrency) or by a central bank (central bank digital currency/CBDC).

Digital currency, when designed and protected by good regulations, offers greater efficiency in the near term and economic stability in the long run. From a policy perspective, digital currency allows a central bank to fully realise its responsibility as sole issuer of the national currency. Digital currency issued by a central bank (CBDC) could operate under the same principles as physical currency. Central banks could regulate digital currency simply and effectively, while only the central bank can make, destroy and circulate digital currency as legal tender. By maintaining supervision simplicity using existing technological advancement, this will increase control of the monetary policies implemented. From a user perspective, digital solutions facilitate secure and efficient digital transactions. Digital currencies would work securely in all payment systems and solve the interoperability problem, which itself could increase the utility of digital financial services.

There is currently growing interest amongst the central banking community and experts to study the possibility of issuing CBDC. Besides the potential impact on

\footnotetext{
${ }^{1}$ Beyond the aforementioned technologies, other technology platforms are also utilised liberally in various industries, including augmented reality (AR) and nanotechnology. In addition, numerous parties are currently linking the IoT with cloud computing services, which combines the use of networked computer technology with internet-based development. This is used to run programs or applications simultaneously across various connected computers. The integration of both will provide sophisticated solutions to future problems.
} 
enhancing payment, settlement and economic transaction efficiency, experts are also focusing on the possible contribution to strengthening monetary policy transmission mechanisms and maintaining financial stability. ${ }^{2}$ The concept of digital currency will affect the central bank mandate. Furthermore, this concept has applications in terms of cyber risk, monetary policy instruments, influencing payments infrastructure in the transaction process, impacting financial stability and others. In the process of implementing digital currency, the central bank must coordinate with various parties, such as the internal and external policy authorities, technology providers, regulators, government and other central banks, which will require careful management.

Ultimately, the world's gone from flat, to fast, to smart, to deep (Friedman 2019). Central bank policy practices and services will also experience a significant paradigm shift. Cloud computing solutions, as an industry that has mushroomed in recent years, allows industries and organisations around the world to take advantage of flexible, scalable and cost-effective solutions. Financial services institutions are reliant on services that support information technology. Therefore, cloud computing is being adopted at scale, with the main advantage of storing massive amounts of data in the cloud that can continue to grow without having to invest in individual servers. Security is also an advantage of cloud computing solutions, making cloud computing compatible with central bank network infrastructure that demands impenetrable security. Moreover, central banks can enhance service quality through the best industry practices without having to invest to improve their own infrastructure.

In short, the future role of central banks will not be as simple as today. Increasingly complex conditions, more volatile global economic conditions, elevated uncertainty and ambiguity have become known as VUCA (Volatility, Uncertainty, Complexity and Ambiguity). In fact, the persistent dominance of uncertainty and ambiguity has led to unprecedented global economic turbulence (novelty), otherwise known by the acronym TUNA (Turbulent, Uncertain, Novel and Ambiguous). Therefore, the characteristics of the issues and challenges faced will change, with a high risk of uncertainty (unpredictable). The causes of the problem created by the policy to be taken is thus unclear (unknown). Consequently, the policy direction taken by economic players, including the authorities and market players, is thereby uncertain. As Donald Rumsfeld once stated, the challenges facing management moving forward are unknown unknowns. ${ }^{3}$

This paper explores salient issues of central banking practices, especially on challenges confronted by central banks in the digital era, lessons learned, as well as their implications. The following section presents challenges and opportunities in the digital era, coloured by digital transformation that significantly affects corporate business models, banking and financial digitalization, and the future of money. The third

\footnotetext{
${ }^{2}$ The argument that CBDC could enhance monetary policy effectiveness lies in the assumption that CBDC paid interest. Nevertheless, an interest bearing CBDC would place pressure on bank deposits. On the other hand, if the CBDC paid zero interest, the CBDC would place pressure on the zero-lower bound (ZLB). Therefore, the potential impact of CBDC on monetary policy must be explored in depth, requiring various central bank efforts to understand such currencies comprehensively.

${ }^{3}$ Delivered by Donald Rumsfeld (US secretary of defence) on 12th February 2002. See Juhro (2019).
} 
section elaborates new realities will be navigated by central banks moving forward, particularly in terms of several technology trends that are developing with rapidity. The last section derives conclusions as well as academic and policy implications.

\section{Digital Transformation: Challenges and Opportunities in the New Era}

In a world characterised by rapid technological advancement, the challenges faced by central banks and other policy authorities moving forward will become more complex, thus demanding and testing the ability of policy authorities to develop innovative new ideas. One of the challenges set to face central banks stems from the central bank's role in terms of managing macroeconomic and financial stability in an era when digital transformation touches various aspects of the economy, including corporate business models, banking practices and the future of currency. Therefore, agile central banks must adapt quickly and appropriately to the changes. The rapid development of innovation and technology will also create massive benefits and risks regarding the future role of central banks. Consequently, it is critical for central banks to monitor and respond quickly in order to manage activity in the entire financial system. For that reason, such environmental changes could potentially broaden the central bank mandate moving forward.

\section{Corporate Business Models}

The rapid pace of industry innovation is bringing enormous benefits to companies that can take advantage, particularly in terms of increasing business productivity and efficiency. A salient future challenge for most businesses will be to discover significant and sustainable new sources of growth or income. Businesses must think outside the box. To that end, transformation is a common term used in the business community, where the transformation strategy implies a change in the business model. The most common form of transformation is digital reinvention. Currently, companies are open to digital reinvention, seeking new revenue sources. For a company, developing something new outside of the core business can provide tangible benefits. In this case, digital transformation is a necessary and critical step. If the business transformation is successful, the company will reap radically higher revenue through top-line growth, productivity, cost efficiency, operational effectiveness, customer satisfaction and others. Transformation combined with an appropriate strategy to leverage breakthroughs will change an ordinary business into a game changing business that can promote sustainable innovation and create new sources of growth (Juhro and Aulia 2019; Juhro et al. 2020).

Digital technology has changed market supply and demand. On one hand, digital technology development has increased access or exposed new sources of supply previously unavailable. On the other hand, digital technology has removed demandside distortions, provided comprehensive information to the consumer and re-bundled aspects of products and services to increase corporate profit. The newly exposed 
supply, combined with newly undistorted demand gives new market makers an opportunity to connect consumers and businesses by lowering transaction costs, while reducing information asymmetry (McKinsey 2017). New supply and demand imply giving consumers what they have always wanted but in more efficient ways. Consumer expectations have increased in line with market development. Companies have tried to meet those high expectations through new and enhanced value propositions. In turn, delivering new propositions requires a significant rethink of the business. Any changes to the business model would impact the value chain, cost structure as well as products and services.

The digital transformation era has also exacerbated labour market polarisation between high and low skilled workers, along with youth unemployment, stagnant income amongst most households and income inequality. Automation facilitated by robotics and artificial intelligence technologies is increasing productivity, efficiency, security and convenience. Various developments and ideas that have emerged in recent years have shown that the future working environment will depend on several factors, such as long-term competitiveness and demographics. Automation may not destroy all jobs, but it will change the labour structure dramatically. Higher skills will be required to enter the labour market moving forward, meaning digitalisation and automation will affect the quality and quantity of jobs. New types of work will change the nature of work and working conditions, including the requisite skills, traditional work patterns and sources of income. Technology is opening the opportunity for countries, developing economies in particular, to unlock new fast-growth sectors and close the gap on advanced economies. At the same time, technology has disrupted the labour market, with broad implications on the quantity, quality and variety of jobs.

\section{Banking and Financial Digitalisation}

Digitalisation is also strengthening the financial system. For instance, the dematerialisation of financial assets has contributed to the emergence of e-commerce platforms. Digitalisation is clearly visible in the payment system. Until recently, retail payments were only available using cash and cheques. Now, however, both have been largely eschewed due to technological development. Innovation in the payment system has evolved, with payment instruments available directly from a smartphone or smartwatch. At first, the public was only aware of the cash payment system for daily activities, but the cash payment system has been sidelined by technological advancement towards more convenient payments. Various cash payment methods have been replaced through digitalisation by e-money, e-banking, credit cards, debit cards and other payment methods. The recent surge of users switching from the cash to noncash payment system demonstrates growing public confidence and trust in payment instruments and institutions. Consequently, demand for a fast, efficient and secure payment system has increased, thereby forcing banks to compete to create more efficient alternative payment systems by exploiting various technological advances. 
For the banking industry, rapid advancement of digital technology has prompted significant changes in the business of banking. Two decades ago, technological innovation centred on internal innovation, yet now technological innovation has penetrated customer and consumer services. In general, the banking industry has adopted two responses to technological advancement, namely digitalisation to provide faster, more affordable and simpler services as well as integration of banking activities into the customers' daily lives. Through myriad innovation, FinTech has helped the banking industry reach a broader consumer base and access customers previously unbankable through the traditional banking system. FinTech has also provided services with lower operating costs, thereby bringing down the costs passed on to the consumer. The various benefits afforded by payment system digitalisation have encouraged central banks to promote banking industry digitalisation more broadly. The benefits include boosting international economic transactions, suppressing the shadow economy, contributing to economic growth (consumption and higher velocity of money) and increasing monetary policy effectiveness in terms of convenient money supply controls and mitigating illegal activity, such as corruption, money laundering, terrorism funding and tax evasion.

Digital transformation, particularly within the payment system, has created opportunities and risks like two sides of a coin that cannot be fully maximised or eliminated. In this case, digital technology can influence monetary policy and financial system stability in a country. The evolving use of digital technology has created numerous economic benefits. First, digital innovation facilitates broader access to financial services. Previously unbanked persons are now able to utilise banking services due to greater convenience and affordability. This means that banking digitalisation has facilitated broader financial inclusion. Second, creating more efficient business processes by lowering operating costs. A digitalised payment system can create products and offer services with greater cost efficiency, thereby lowering the costs passed on to the consumer. In addition, the use of technology has expanded the variety and choice of services available to consumers. Third, potential security gains through technology. Most banking activities can be automated through the use of technology. Business services and monitoring are also more convenient and secure because the bank can monitor all activities with ease.

Notwithstanding the benefits, payment system digitalisation also creates risks that could disrupt financial stability in a given jurisdiction or globally. First, the threat of cybercrime increases when all banking processes are automated. Technological advancement is always accompanied by larger cyber threats. Therefore, rapid technological advancement in the banking industry must be accompanied by sophisticated cyber security efforts to avoid massive losses triggered by cyber-attacks. Second, the potential impact on monetary policy effectiveness and financial system instability. Technological advancement facilitates higher asset volatility that could undermine or at least delay the impact of tighter monetary policy. Meanwhile, broader use of technology in the banking sector, accompanied by the emergence of various new industry players, could increase cyber-attacks and the risk of bank runs facilitated by fast and convenient transfer services, which have created the threat of financial system instability. Third, the erosion of consumer protection. In the era of banking 
digitalisation that prioritises convenience in transacting, coupled with the automation of all service processes, consumer protection has been eroded. Larger cyber-attacks and greater access to confidential consumer data have created massive consumer losses.

\section{Future of Money}

The fundamental consequence of digital transformation on the existence and role of central banks refers to the future of money. Payment transaction convenience supported by various existing facilities will reduce cash use. Cashless payments, such as e-money, e-banking, credit cards and debit cards, create inherent advantages, thus usurping cash payments. This trend is leading towards a cashless society, namely a significant reduction of cash use. Payment instruments generally have strong network externalities, where a larger network of users increases the utility for each user. For example, if several payment instruments are accepted widely in the retail space, the utility of such instruments for the users will increase. In practice, cash will lose its network externality, making it more difficult to obtain cash moving forward (Ingves 2020). ${ }^{4}$

On the other hand, since Nakamoto (2009) developed blockchain technology, start-ups have sought to create alternative financial transaction systems that have hitherto remained the domain of the banking industry. The emergence of peer-topeer $(\mathrm{P} 2 \mathrm{P})$ transactions and cryptocurrency have ushered in a new era of convenient alternative services for the public, including financial transactions that were previously the preserve of the banking industry. Cryptocurrencies are attractive to the public, particularly in terms of potentially higher prices moving forward as well as the freedom and speed afforded by blockchain technology without the involvement of a third party, namely banking. Therefore, there are no rules or regulations that could potentially impede the payment process. For example, when initiating an international transfer, the process no longer requires several working days, instead taking just hours or even minutes. In addition, cryptocurrency obviates the possibility of money counterfeiting. A problem with using cash or credit cards is vulnerability to theft and fraud. Cryptocurrency, however, is created using a unique computational algorithm, which is almost impossible to hack.

The emergence of cryptocurrencies has increased competition amongst payment service providers. Therefore, financial authorities must intervene to ensure financial system stability. Cryptocurrencies are small in scale with limited interconnectedness and, thus, systemic risk concerns are negligible. Nevertheless, without supervision by the relevant authorities, cryptocurrencies could become embedded in the main financial system and threaten financial stability. Most importantly, cryptocurrency cannot erode the central bank's role as custodian of public trust. Private digital tokens obfuscated as currency cannot destroy public confidence in the central bank. Although cryptocurrencies are considered high risk and with the potential to disrupt

\footnotetext{
${ }^{4}$ Several banks in Sweden, Norway and Denmark, for example, have recorded cashless transactions exceeding $90 \%$, or even $97 \%$ when peer-to-peer (P2P) products are reflected. This trend will be replicated in all countries due to the need and consequences of rapid technological innovation. This is inevitable, including central banks and financial supervision institutions (Wijaya 2019).
} 
economic stability, it cannot be denied that they have unlocked a new era of currency digitalisation.

Moving forward, digital currency will become more attractive than cash, where convenient access and flexibility will override public demand for cash. Access to cash to and from the central bank is limited to traditional operating hours, namely less than $24 \mathrm{~h}$ per day and only five days per week. Many central banks already offer real-time or near real-time settlement available 24/7. There are, of course, exceptions, such as cross-border retail payments, which are generally slower, less transparent and more expensive than domestic retail payments. In this regard, central bank efforts lag behind the potential afforded by digital currency.

Under such conditions and considering the characteristics and potential risks associated with cryptocurrencies, various academics have opined that central banks must utilise digital technology to increase use of central bank digital currency (CBDC). Prevailing opinion is that CBDC would facilitate risk-free payments for the public and create digital instruments for daily transactions. In addition, CBDC offers a viable alternative to cryptocurrencies, providing a higher level of security. In reality, however, central bank reaction to developing digital currency is cautious and defensive. Nevertheless, the future development of digital currency is not a choice but an inevitability. Moving forward, the availability of digital currency in the form of tokens or accounts held directly by the central bank is required due to FinTech developments, such as bitcoin and various other advances in other sectors that will persist. Therefore, studies regarding the pros and cons of issuing digital currency will continue to be published (Murray 2019; Panetta 2018; Yanagawa and Yamaoka 2019).

In the case of Indonesia, for instance, the monetary policy authority, e.g., Bank Indonesia (BI), always pays attention to the urgency of adopting digital currencies. BI considers public behaviour or demand for digital money, which can be in the form of cryptocurrency, or just digital money, which is currently very widely used; and its potential impact on the macroeconomic stability and growth. BI prohibits cryptocurrencies (such as Bitcoin) from being used as a means of payment, because the official means of payment (legal tender) in Indonesia is the rupiah. However, cryptocurrency still can be used as traded goods. ${ }^{5}$

$\mathrm{BI}$, in a forward-looking perspective, also plans to issue a digital currency or $\mathrm{CBDC}$ in the future. In this case, there are three considerations in this CBDC issuance plan (Bank Indonesia 2021). First, digital currency is the authority of BI as the central bank. This is a mandate from the 1945 Constitution (UUD), which is spelled out through the Currency Act and the Bank Indonesia Law. In this context, BI plans to issue rupiah $\mathrm{CBDC}$ as legal tender in the future. As a legal payment instrument, this rupiah CBDC will be prepared 'end-to-end', both in terms of design and circulation, as BI does for banknotes and cards, both debit and credit cards. Second, the CBDC will support the implementation of monetary, macroprudential and payment

\footnotetext{
${ }^{5}$ The Commodity Futures Trading Regulatory Agency (Bappebti) has issued Regulation number 5 of 2019, concerning technical provisions for the implementation of the physical market for crypto assets on futures exchanges in Indonesia.
} 
system policies, including the preparation of integrated financial market infrastructure, foreign exchange, and the financial sector. Third, BI will really consider the technology to be utilised optimally. This, among others, can be done by observing and adopting which technologies or platforms are used by other countries. ${ }^{6}$

The impact of CBDC on monetary policy effectiveness is heavily dependent on whether CBDC pays interest. Account-based CBDC that pays interest would unavoidably impact monetary policy implementation and transmission. An interest bearing CBDC would allow central banks to target negative interest rates in response to dire economic conditions as well as avoid or at least minimise the need for unconventional monetary policy. In other words, monetary policy could become fully symmetrical. Interest rates could be adjusted downwards without limit, while monetary policy would not change operationally. Inflows and outflows would be accommodated automatically and the impact on reserves neutralised similar to current paper money mechanisms. The difference lies in the central bank's greater ability to stabilise prices and output. ${ }^{7}$ Another monetary policy benefit of account-based CBDC is direct control over interest rates by the central bank. Account-based CBDC provides central banks with a direct channel to the interest rates faced by households and businesses, and avoids potential unwanted biases that can happen under the current system, where central bank target movements are distorted through interest rates in the capital markets and commercial banks. Account-based CBDC would also offer real-time interaction between economic activity and changes in monetary policy.

From a financial stability perspective, one of the benefits of CBDC replacing cash would be to eliminate the risk of bank runs. If a central bank issued account-based CBDC, where the function is similar to term deposits at commercial banks, this would eliminate the risk of bank runs during periods of financial distress because CBDC is managed and guaranteed directly by the central bank and, therefore, could never collapse. Fundamentally, CBDC is free from credit risk and liquidity risk. Furthermore, account-based CBDC is fully guaranteed and secured by risk-free central bank securities, making it safer than other types of currency. Another benefit of issuing CBDC for the central bank would be latitude in terms of controlling credit growth and existing sources of debt financing within the economy. ${ }^{8}$

\footnotetext{
${ }^{6}$ The issuance of the CBDC is an integrated part of the development strategy of the Indonesia Payment System Blueprint of 2025 (Bank Indonesia 2019).

${ }^{7}$ Currently, however, the most binding constraint to symmetrical monetary policy is the ability of households and businesses to circumvent the impact of negative interest rates by converting term deposits and financial assets into cash.

${ }^{8}$ Another consideration regarding the future use of CBDC is whether paper money will continue to circulate, but commercial banks may remain and compete freely for the retail sector. Market pressures would cause a concentration of term deposits at commercial banks as a means to fund loans extended to households and businesses. The critical difference from a financial stability perspective would be more limited in terms of incompatible maturity and liquidity.
} 


\section{New Realities and Lessons Learned}

It is common knowledge that central banks are going to face new realities moving forward, particularly in terms of several technology trends that are developing with rapidity. Therefore, central banks must work diligently to observe the potential benefits and risks of each technology as prospective innovative options to be exploited.

First, the ability of technology to use big data and big data analytics to design quantitative algorithms that transform data into comprehensive information for effective consumption. All FinTech players use big data analytics for their products and services to learn about their consumers and garner input when making business decisions. To that end, big data analytics can help bridge market supply and demand by contributing and innovating business models for financial technologies. Second, artificial intelligence allows computers or mobile applications to perform tasks typically requiring human intelligence, such as feeling, understanding, behaving, learning and taking final decisions. This technology has massive potential to stimulate innovation in all business sectors and financial services. Third, blockchain is the backbone of cryptocurrency and central bank digital currency, in which its development will determine how far central banks can play a strategic role in the digital era with an increasingly decentralized financial system. Finally, cybersecurity, namely a technology development strategy to identify, authenticate, integrate and facilitate information systems and electronic data. The hacking of business units belonging to financial technology players must be meticulously guarded against to safeguard system security.

Although digital technologies are believed to help businesses become more productive, create more job opportunities and improve public services; we must ensure the economy receives optimal benefits from the digital dividend. This is possible by building solid foundations of analogue complements through strong regulations to nurture innovation, develop skills to optimise the opportunities that arise and institutional strengthening to ensure the authorities can provide public services accountability (World Bank 2016).

Therefore, authorities and other stakeholders must consider various aspects when taking action against future technologies and innovations that are constantly evolving by building comprehensive understanding of digital economic and financial practices in accordance with respective jurisdiction (Berger 2017a, b). Mapping the innovations based on the characteristics of each respective services provider (new technologies or updated technologies). Preparing clear rules and regulations to accommodate new activities and ensure risk control, minimal regulations to manage moneylaundering, consumer protection and consumer data, applied to all financial services providers and payment platforms. Innovation in the financial sector is a worldwide phenomenon, and services providers work across borders. Therefore, it is important to preserve inter-authority cooperation and coordination when developing regulations to be enforced globally. Equally important, as a regulator, the central bank 
must utilise technologies and other analytical skills to develop toolkits to increase supervision capacity.

Of the diverse strategies that a central bank might have to undertake, fundamentally, central banks will need to take comprehensive and holistic actions as they face various new technology-driven challenges that will disrupt their businesses in ways we cannot even imagine right now. The future of unknown-unknowns shall remain a challenge, requiring central banks to ensure resilience and efficiency by creating reliable and nimble organisations in response to any environmental changes (PwC 2016). Addressing such developments, central banks must clearly understand the dynamics and prepare the full panoply of tools at their disposal. Central banks require an organisational structure and human resources agile to change. The qualities of competent human resources must be accelerated to keep pace with rapid technological development rather than increased business as usual. Central banks must remain ahead of the curve, thus requiring an agile non-hierarchical organisational structure to respond quickly to shifts and changes in the environment.

Ultimately, strategic environmental change after the crisis, which will inevitably accelerate in the digital era moving forward, will determine how the economic system works as well as the presence and mandate of the central bank.

The following lessons learned can be derived from the above discussion. First, experience from various financial crises has shown that central bank concerns over maintaining financial system stability will continue to increase. New monetary and financial policy instruments must be developed and integrated into a policy mix strategy, which will ensure a broader central bank policy impact in the real sector. Such ideas contradict the views of some, however, who have stated that financial crises occur due to a central bank mandate that is too broad, giving the impression that the central bank's task is becoming less effective. Therefore, institutional strengthening of the central bank is unavoidable. Furthermore, central bank independence must be upheld as sacrosanct, accompanied by accountable and transparent policy implementation. In addition, stronger coordination is required amongst policy authorities within their respective jurisdictional corridors, supported by an effective communication strategy to articulate policy messages unequivocally to financial market players and stakeholders.

Second, with greater economic openness and strong interlinkages between economic activity in the real and financial sectors, the dimension of international interconnectedness in the globalisation is an emergent aspect that will feature prominently in central bank policymaking moving forwards. Therefore, central banks must prepare a policy strategy and response from the perspective of a hyperconnected and borderless world. The challenge of unknown-unknown environment demands stronger international cooperation initiatives to build catalytic collaboration and ensure inclusive and sustainable economic prosperity.

Third, as companies continually hone their business models in response to environmental changes, central banks must also be able to adjust their business processes to strategic environmental changes in the TUNA era. Central banks need to work hard not only to optimise the benefits afforded by digital technological advances but also to remain relevant in the era of digital transformation, which will only continue to 
accelerate moving forward. While the central bank policy mix is still a viable strategy, central banks are required to operate 'beyond conventional wisdom', with novel practices. Non-hierarchical business processes and multidisciplined procedures must be adapted by central banks through integrated policymaking. The introduction of new technologies in various economic lines has opened the door to new economic threats. Cyber-attacks have enormous potential to threaten financial systems and infrastructures in a country. Therefore, it is critical to develop systemic resilience through a reliable supervision and cybersecurity system. Clear supervision and regulation to overcome cyber-attacks, the ability of cyber security to detect attacks quickly and developing solid systems and structures are a necessity moving forward.

\section{Conclusion and Implications}

As explained above, navigating central banking practices in the digital era, blighted with high uncertainties, is a very challenges task that requires the central bank's ability to create breakthroughs and orchestrate policy innovations. Hence, optimizing the benefits of technological advances and remaining relevant in the digital era must be the anchor of the central bank's strategy going forward.

Tough problems always provide good opportunities for us to learn. The series of previous economic crises have spawned new economic theories or ideas, including next practices. In this regard, rapid changes in the strategic environment have fundamental implications on theories underlying central bank policymaking. Likewise, policymaking and implementation practices at various central banks have undergone change and strengthening that require development of the underlying theories. 'Practice ahead of theory', as extolled by King (2005). In other words, this evolution is influenced by reciprocity between the development of monetary economics and financial theory in academia with the ideas and concepts underlying policymaking practices in the central bank.

Academia, in its efforts to explain or offer solutions to the problems, has contributed an abundance of conceptual and theoretical ideas regarding various economic phenomena and behaviours in society. Such theoretical thinking is advanced and profound at the philosophical-conceptual level, supported by the use of advanced quantitative methods and empirical studies, - although often based on certain assumptions to simplify complex economic behaviours in the real world.

In many central banks, on the other hand, various concepts and innovations have occurred in the discipline of policymaking as solutions to complex financial and economic problems that have emerged and developed quickly. In many cases, policy innovation is also facilitated by close interaction within the central bank community at various global and regional forums and meetings. Theoretical ideas that develop in the academic world certainly form the basis of central bank policymaking. Nonetheless, the complexity of real-world problems often demands an innovative policy response from the central bank, which provides further impetus for the academic community to test the underlying theoretical merit and empirical evidence. 
Therefore, in a world characterised by rapid technological advancement, the challenges faced by the central bank and other policy authorities moving forward will become more complex, thus demanding and testing the ability of policy authorities to develop innovative new concepts as the authority/regulator, which is always relevant. One challenge central banks will face stems from their role to maintain financial stability in the era of digital transformation from various economic aspects, including banking, currency and core business. Central banks must remain agile to adapt quickly and appropriately in the face of change. Rapid development in terms of innovation and technology creates large benefits and risks for the central bank function moving forward. Therefore, it is critical for central banks to develop early monitoring and rapid responses in terms of managing activities in the entire financial system. Consequently, the various environmental changes will also influence the future mandate of the central bank.

The rapid evolution of policy and institutional ideas in the central bank environment, encompassing the academic theories and innovative policy responses, must also be reviewed, studied and documented. The conceptual thinking underlying the central bank policy response is a critical reference for other central banks and policymakers to draw lessons from conventional practices and the best practices to resolve the problems faced, and for the academic community to explain and develop the theories in more depth. On the other hand, the theories that continue to flourish in academia are a useful reference for central banks to assist the policymaking process in response to the unfolding problems.

\section{References}

Bank Indonesia (2019). The Indonesia Payment System Blueprint of 2025, Bank Indonesia: Navigating the National Payment Systems in the Digital Era, Jakarta.

Bank Indonesia (2021), The Bank Indonesia Governor's statement on CBDC issuance, Retrieved from: https://money.kompas.com/read/2021/05/26/122037826, May.

Barro, R.J. and Gordon, D.B. (1983), A Positive Theory of Monetary Policy in a Nature Rate Model, Journal of Political Economy 91(4):589-610, February.

Berger, R. (2017a), Digitalization Threatens Jobs and Creates Jobs, Retrieved from: file:///C:/Users/asus/Downloads/roland_berger_future_of_work.pdf.

Berger, R. (2017b). Central Banking IT of The Future. Roland Berger GMBH. All rights reserved.

Collin, J., Hiekkanen, K., Korhonen, J.J., Halén, M., Itälä, T., Helenius, M. (2015). IT Leadership in Transition-The Impact of Digitalization on Finnish Organizations, Research rapport, Aalto University, Department of Computer Science.

Friedman, Thomas L. (2019, March 15), Technology Moves in Steps. Retrieved from McKinsey: https://www.mckinsey.com/featured-insights/future-of-work/thomas-1-friedman-tec hnology-moves-in-steps.

Ingves, S. (2020), Monetary Policy in A Changing World, Sveriges Riskbank Governor speech at Business Arena. December.

Juhro, S.M., Ed. (2019), Transformational Leadership: Konsep, Pendekatan, dan Implikasi pada Pembangunan, 2nd Ed., Bank Indonesia Institute - Jakarta.

Juhro, S.M. and Aulia, A.F. (2019), New Sources of Growth: the Role of Frugal Innovation and Transformational Leadership. Bulletin of Monetary Economics and Banking, 22(3). 
Juhro, S.M. \& Goeltom, M.S. (2015), Monetary Policy Regime in Indonesia, in Kohsaka, A. (Ed.), Macro Financial Linkages in the Pacific Region, Routledge - London.

Juhro, S.M., Aulia, A.F., Hadiwaluyo, D., Aliandrina, D., \& Lavika, E. (2020), The Role of Catalytic Collaboration in Leveraging Transformational Leadership Competencies to Generate Sustainable Innovation, International Journal of Organizational Leadership 9-1.

Khan, S. (2016). Leadership in the digital age: A study on the effects of digitalisation on top management leadership. Stockholm Business School Master Thesis, Spring.

King, Mervyn (2005), Monetary Policy - Practice ahead of Theory, Text of the Mais Lecture, City University, London, May.

McKinsey (2017), Digital Reinvention. Retrieved from: https://www.mckinsey.com/ /media/mck insey/business\%20functions/mckinsey\%20digital/our\%20insights/ashx.

Murray (2019) Murray, J.D. (2019), Central Banks and the Future of Money, C.D. Howe Institute.

Nakamoto, Satoshi (2009), Bitcoin: A Peer-to-Peer Electronic Cash System, Retrieved from: https://translate.googleusercontent.com/translate_c?hl=en-US\&sl=en\&tl=id\&anno=2\&prev= search\&client=srp\&u.

Panetta, F. (2018), 21st Century Cash: Central Banking, Technological Innovation and Digital Currencies. Speech of Deputy Governor of the Bank of Italy.

PwC (2016), Central Banking 2020: Ahead of the Curve. www.pwc.com/banking.

Schwab, K. (2017). The Fourth Industrial Revolution. London: Portfolio.

Warjiyo, Perry (2021), Rethinking Macroeconomy and Central Banking in the New Normal, Bulletin of Monetary Economics and Banking, Special Issue 2021, pp. vii-xiv.

Warjiyo, Perry and Juhro, Solikin M. (2019). Central Bank Policy: Theory and Practice. Emerald Publishing - London.

Wijaya, K. (2019), Mata Uang Digital Bank Sentral. Artikel dalam Majalah Infobank, Edisi Februari. World Bank (2016). Digital Dividend, World Development Report.

Yanagawa, N. and Yamaoka, H. (2019), Digital Innovation, Data Revolution and Central Bank Digital Currency. Bank of Japan Working Paper Series, No. 19-E-2.

Open Access This chapter is licensed under the terms of the Creative Commons AttributionNonCommercial-NoDerivatives 4.0 International License (http://creativecommons.org/licenses/bync-nd/4.0/), which permits any noncommercial use, sharing, distribution and reproduction in any medium or format, as long as you give appropriate credit to the original author(s) and the source, provide a link to the Creative Commons license and indicate if you modified the licensed material. You do not have permission under this license to share adapted material derived from this chapter or parts of it.

The images or other third party material in this chapter are included in the chapter's Creative Commons license, unless indicated otherwise in a credit line to the material. If material is not included in the chapter's Creative Commons license and your intended use is not permitted by statutory regulation or exceeds the permitted use, you will need to obtain permission directly from the copyright holder.

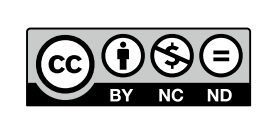

